\title{
Relacionalidad didáctica desde el aula universitaria. Principios hacia una educación más humana
}

\author{
Didactic relationality from the university classroom. Principles towards a \\ more humane education

\section{Relações didáticas da sala de aula da universidade. Princípios para uma educação mais humana}

Francisco David Oviedo Silva

Magister en motricidad humana

Docente Universidad Autónoma de Chile, Talca foviedos@uautonoma.cl

Manuel Matus Pinochet

Magister en motricidad humana

Docente Universidad Autónoma de Chile, Talca mmatusp@uautonoma.cl

Mirko Aguilar Valdés

Profesor de educación física. Licenciado en educación Docente Colegio Liceo Abate Molina, Chile, Talca maguilarvaldes@gmail.com

\section{Resumen}

Al hablar de didáctica, emergen interrogantes respecto a lo que se entiende por conocimiento, cuándo y cómo se comparte. Este estudio pretende desbordar el fenómeno de la formación docente de la carrera de pedagogía en educación física de la Universidad Autónoma de Chile, sede Talca, contexto que acentúa su accionar docente desde una mirada compleja y fenomenológica, "caminando" en relación al bucle didáctica - relacionalidad educativa. La metodología utilizada se desplego desde un enfoque cualitativo con énfasis en la interpretación, buscando profundizar en los resultados que se orientan en busca de una educación más humana desde la motricidad educativa, con acciones orientadas desde y para los estudiantes, bajo una visión actualizada del fenómeno educativo que considere el constante cambio que vive éste, desplegando lo complejo del fenómeno didáctico y de las relaciones que emergen, dando sentido y significado a este entramado proceso. 
Palabras claves: Didáctica - relacionalidad didáctica - motricidad educativa

\begin{abstract}
When dealing with Didactics, certain inquiries are raised concerning what it is understood as knowledge, when and how it is taught. This Research aims at disclosing the teaching instruction phenomenon at the Physical Education Teaching program at Universidad Autónoma de Chile, Campus Talca, within a context that stresses teaching practices from a complex and phenomenological point of view, by literally 'walking' the DidacticsEducative Relationality loop. The methodology used was displayed from a qualitative focus, with emphasis on the interpretation, aiming at profounding on guiding results, which may seek a more human education from the educative motricity, with actions aimed from and for the students, under a current vision from the educational phenomenon, that may consider the constant flux of changes at which the student is inserted, displaying complex areas from the didactic process and from the relations that emerge from it, making sense and meaning to this high complex wired system.
\end{abstract}

Keywords: Didactics - didactic relationality - educational motricity

\title{
Resumo
}

Ao falar de didática, surgem questões sobre o que é entendido pelo conhecimento, quando e como é compartilhado. Este estudo tem como objetivo dominar o fenômeno da formação de professores na carreira de pedagogia na educação física na Universidade Autônoma do Chile, campus de Talca, um contexto que enfatiza seu ensino de uma visão complexa e fenomenológica, "caminhar" em relação ao laço didático - relacionalidade educacional. A metodologia utilizada foi desenvolvida a partir de uma abordagem qualitativa com ênfase na interpretação, buscando aprofundar os resultados orientados em busca de uma educação mais humana do motor educacional, com ações orientadas para e de estudantes, sob uma visão atualizada do fenômeno educacional que considere a constante mudança que esta vive, exibindo o complexo do fenômeno didático e as relações que emergem, dando significado e significado a esse processo em rede.

Palavras-chave: didática - relacional didáctica - motricidade educacional

\section{Introducción}

"Aquel que pretende aprender los fenómenos humanos y específicamente, la forma como los niños comprenden y aprenden, debe antes que todo aprender a observar" (Vayer y Roncin, 2000, p. 11).

Creemos en una educación más humana, que se viva desde y para el humano, con visiones actualizadas del fenómeno educativo y se viva la didáctica desde la ciencia de la motricidad humana, resaltando el sentido y significado de la emergencia relacional; asimismo, sustentada en una amplia y actualizada base epistemológica, acorde al saber contingente de la acción educativa, reinterpretando constantemente a los sujeto y contexto. Creemos en una didáctica relacional que se reconstruye a diario y se enriquece de incertezas, no pasiva ni unidireccional, sino un 
acercamiento posible, una manera de observar, leer, de comprender situaciones.

La educación física que se está desarrollando en muchas escuelas y universidades, cuenta con un modelo didáctico poco permeable, que se replica con superficiales cuestionamientos y propuestas de bajo impacto. Sin embargo, somos los docentes los llamados a reflexionar sobre nuestro hacer y ser como ejes articuladores del proceso educativo, profundizando en una didáctica centrada en la relacionalidad docente-discente-ecos, intentando crear un ambiente más humano.

Se plantea como objetivo del trabajo: comprender el accionar didáctico desde la relacionalidad didáctica en la carrera de Pedagogía en Educación Física, Universidad Autónoma, Talca.

\section{Didáctica}

La didáctica nace como una disciplina rigurosa de estudio y acción medular en el proceso educativo (Mata y Medina, 2005; Medina y Salvador, 2002). El enseñar y aprender han sido entendidos como un actuar docente "que sabe", pues posee el conocimiento y habilidades para la entrega de los temas que domina y "él que aprende" estudiante, como receptor "pasivo" del conocimiento. Freire supera la concepción tradicional y plantea que "quien forma, deforma y re-forma al formar, y quien es formado se forma al ser formado", lo que equipara y reconfigura esta relación (Freire, 1997, p.25).

Docente y discente viven su discurso y reflexionan en su hacer desde su historia y lo compartido cada día, el contenido les permite diferenciar qué aprender, pero sin dejar de lado los diferentes aprendizajes que fruto de la relación se encarnan (Mata y Medina, 2005). La didáctica actúa directamente en el desarrollo de los encuentros educativos, facilitando la acción educativa gracias a su fundamentación, estructura y planificación.

La ciencia de la motricidad humana pone énfasis didáctico en lo sistémico y complejo de la acción humana, ya sea deportiva, artística, laboral o educativa; es en esta última, donde pondremos acento para pasar de un determinismo metodológico hacia una didáctica de posibilidades de la motricidad como campo epistemológico propio (Toro, 2007), mudanza en la mirada acerca del fenómeno que permite emerger propuestas de superación conceptual y de sentido. La "paidomotricidad", por ejemplo, (de paidos -niño- y paideia educación-) permite integrar y redefinir al docente y discente (Trigo, 2006).

Preguntas sobre el qué, cómo y cuándo del actuar didáctico, nos entregan luces sobre los diferentes actores que dan dinamismo al mundo educativo, como también a las manifestaciones y frutos de este fenómeno, proyecciones histórico personales de docentes y estudiantes, sujetos clave para crear y re-crear la experiencia educativa constantemente (Freire, 1997; Morín, 2001), todo ello desde una mirada compleja emergente (Mata y Medina, 2005).

\section{Relacionalidad}

"Es necesario comprender la acción humana como un nudo relacional (relacionabilidad o relacionalidad) y no como el resultado del individuo singular. Es en este nudo relacional donde el sujeto y su 'conducta en relación' se despliegan" (Toro, 2011, p. 158). 
La relacionalidad educativa debería tener principios por los cuales andar, una actitud de buena convivencia que sea acogedora y reconozca al otro en un convivir, legitimando al otro, corrigiendo solo su hacer y no su ser (Maturana, 1991). La construcción del aprendizaje desde una relación horizontal es equitativa, otorga responsabilidad tanto en conocimientos como en experiencias, el profesor desde su rol de experto guía el proceso, disminuye su protagonismo, poder y control (Bertoglia, 2005).

La naturaleza intrínseca humana de relacionarnos con otros, el compartir que usualmente es invisible dada su condición, requiere del docente hacer carne (vivir) la importancia de la interacción con otro en una dinámica social (educativa) compleja. Freire (2005), plantea que nadie debiera obligar a otro, y que se debe comprender que nadie se educa solo; el acto educativo es en comunidad, por ello, la apuesta es a una reconfiguración de las relaciones, dando importancia medular a la interacción docente-discente-ecos, claves todos de un proceso dinámico y cambiante (Sidorkin, 2007).

\section{Metodología}

En el proceso del comprender, es preciso vincular al sujeto en los espacios educativos, permitiendo adentrarse y avanzar a la comprensión de una realidad a estudiar en un contexto determinado.
La mirada cualitativa fenomenológica se envuelve por una dinámica recursiva sustentada en la reflexión permanente, con una mirada en el proceso y lo cotidiano. En el contexto educativo se destaca la interpretación, permitiendo un encuentro metodológico con los sujetos en su contexto y situación natural (Taylor \& Bogdan, 1996; Rodríguez, Gil \& García, 1996; Flores, 2009), la hermenéutica permite aprehender "toda expresión de significado, ya sea una manifestación (verbal o no verbal). También se identifica desde una doble perspectiva, "como acontecimiento material o como una objetivación inteligible de significado" (Murcia \& Jaramillo, 2008, p. 67).

Los participantes de este estudio fueron estudiantes de $2^{\circ}$ y $3^{\circ}$ año de la carrera de Pedagogía en Educación Física, que cursaron los módulos de Motricidad Humana y Educación Física de Base, más el docente de las cátedras, periodo 2011. Se resguardó su anonimato (para el proceso de análisis se crearon nombre ficticios). La técnica utilizada fueron entrevistas semiestructuradas (dos) y grupos focales (cuatro), con 12 participantes cada uno.

Luego de la transcripción se redujo la información, desde un análisis inductivodeductivo, con categorías abiertas y axiales. En el análisis se tomaron las referencias con mayor frecuencia y peso discursivo, generando un encuentro teórico e inspiración para la reflexión. 
Figura 1: Resumen categorial

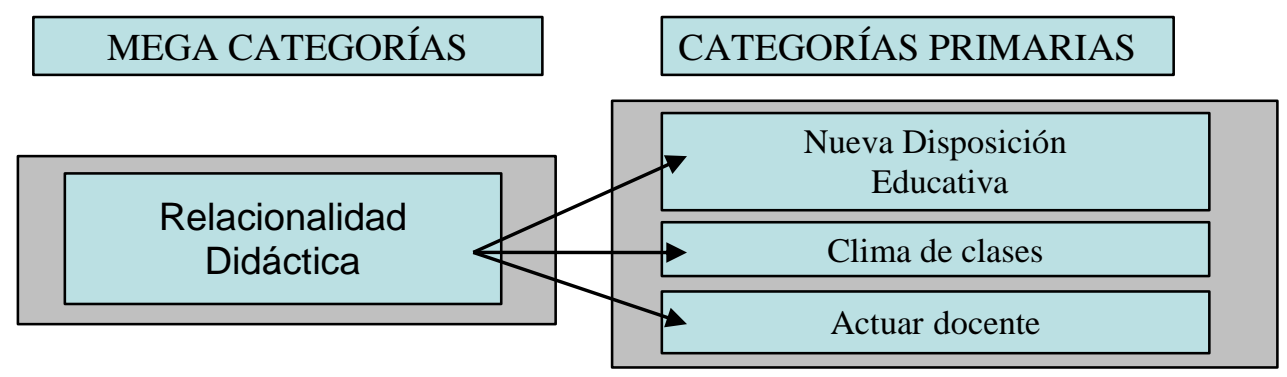

\section{Análisis}

\section{Categoría nueva disposición educativa}

Un cambio en el paradigma educativo, enfrenta al docente a reconfigurar y reorientar su actuar, el pensamiento complejo da pauta a una nueva mirada educacional que busca más allá, orientando su quehacer a un futuro de respeto humano en su condición de ser vivo (Morín, 2001).

Ahí va mi explicación, por ejemplo, si llega una niñita a clases enferma no le podemos pedir lo mismo que a una niñita que está bien, no importa si ella da siete vueltas, sino que al comienzo daba dos y ahora está dando tres (Jorge, A18).

Orientaciones para un nuevo actuar mudan la visión de rendimiento que se encarnó bastante tiempo en nuestra área de conocimiento -la acción-, nos invitan a considerar la carencia individual que cada sujeto tiene en el aprendizaje y respetar los tiempos históricos personales que los actores educativos comparten (Souto, 2003); "Me acerco más al que está con problemas, me acerco al desprotegido, al que tiene menos personalidad, antes no, yo en mis clases simplemente estaba con los que rendían y el que no rendía, que lata" (Cesar, A15).
Mirar nuestra relacionalidad invita a reconocernos como educadores y compartir desde la cotidianidad y naturalidad que generan las relaciones sociales, generando aprendizajes desde lo cotidiano, tanto en los estudiantes como el docente.

\section{Categoría clima de clases}

El clima de clases en el acto cotidiano de encuentro da identidad a cada instante con mensajes sin palabras, toques sin tocar, indicaciones que puntúan y orientan la dirección de lo conversado entramando el acto de compartir en una hebra de acciones y sentidos: "tú sabes la vinculación que hay con ellos cierto, afectuosa, siempre del respeto, pero con cariño, y que me agradecen después que se terminan los temas, profe muchas gracias, se van contentos" (Cesar, A32).

La relacionalidad trasciende desde espacios "no formales" al aula misma, la importancia de la inclusión y respetar la identidad de cada estudiante, permite entrar en dinámicas de respeto hacia otra persona y luego, dentro del rol que desempeña (Freire, 2005).

Creo que tienes razón, porque a mí una de las cosas que me apasiona en este tema, no sé si te has dado cuenta, es que me vínculo con los más malilla de aquí, soy 
más amigo de ellos y eso es un modelo que ellos van a encontrar en el colegio y con los más malillas también van a tener que vincularse y ser cómplices de ellos" (Cesar, A41).

En muchos casos la minoría maneja los contenidos o la mayoría da esbozos de dominarlos, la mirada se orienta al que "no sabe", su punto de partida desde su configuración como sujeto lo sitúa ni como más ni menos que sus compañeros, lo importante es que el estudiante conozca donde está iniciando su caminar.

"La convivencia, sí, la convivencia y la diversión, eso es fundamental en una clase entretenida" (Juan y Dany, A24). Superando visiones clásicas para dar paso a nuevas instancias relacionales, encuentros donde el juego, la alegría, reflexión, trabajo toman un tono particular de identidad relacional que emerge de los mismos sujetos, donde las acciones se hacen desde uno, para uno y con los demás, desde la libertad y la autorregulación de encuentros intersubjetivos.

A mi forma de pensar, ahora la libertad que daban los profes era más de autonomía, hacer algo por mi voluntad porque yo quiero hacerlo, no llegar a clases a las ocho porque el sistema me lo exige, es porque yo quiero llegar, es porque me nace, es porque hay algo que me motiva como persona, llegar a la hora y no atrasado (Karina, A26).

El acto educativo y las relaciones que emergen, marcan el cómo nos vemos y nos ven los estudiantes, también cuando estamos en otros contextos, la credibilidad y clima de los encuentros es crucial para el aprendizaje y dar espacio a conversaciones de pasillo y/o saludar al caminar, extienden la conexión y el vínculo de la clase, que en algunos casos es limitada en sus horas y espacios:

Porque a veces los chiquillos me hacen algunas observaciones y me dicen, profe no está contento, pero no es por lo que está pasando en el contenido en la clase, sino que eso me lo dicen fuera de la clase, me ven caminar y no me ven contento y según ellos yo era antes diferente (Cesar, A11).

\section{Categoría actuar docente}

Tener un telón de fondo, un sustento argumentativo que engrana la acción con lo que crees, da tranquilidad para afrontar con más seguridad las dudas y desviaciones que pueden surgir en el quehacer educativo desde la motricidad humana.

El haber hecho el magíster en motricidad humana me ha permitido, navegar de una manera más tranquila, sin tanta incertidumbre, porque creo que tenemos más fundamento para decir que se estaba por el camino adecuado, o a veces cuando se está por el camino inadecuado (Cesar, A1).

Esa tranquilidad permite avanzar sobre el accionar, mudando el cómo interactuamos en los encuentros, generando posibilidades que el estudiante pueda descubrir y forjar su propia visión y aprendizaje.

Soy un ser humano deficitario de ciertas habilidades, si se quiere, producto que en mi historia no hubo nadie que me pudiera permitir un desarrollo adecuado, soy carente de situaciones que hoy día podría tener y producto de la irresponsabilidad de muchos que me formaron (Cesar, A9). 
La responsabilidad de aprender, por más que el docente comparta, será tarea del estudiante, tomar y darle identidad al proceso.

Entonces intento que los chiquillos también estén emocionados de manera permanente, vinculando claro el contenido, vinculando el que nos convocó, o sea a la clase que vienen conmigo nos convoca la temática que se va a tratar, no por que quieran libremente venir a conversar conmigo y yo tampoco con ellos (Cesar, A35).

Es desde la emocionalidad donde el actuar docente va tomando fuerza, creando instancias que den cuenta de lo relevante que puede ser lo que está compartiendo en ese momento. Con respecto a la evaluación, el actuar docente se concibe desde su inicio como un acuerdo orientado por una pauta flexible en su dinámica, que considera el proceso, priorizando la superación contante, cambio y evolución de los aprendizajes, por sobre los resultados directos y absolutos.

\section{Reflexiones finales}

"Nuestra realidad no es otra cosa que nuestra idea de la realidad" (Morín, 2001, p. 45).

Queremos dar cuenta de lo cercana que es la didáctica, rompiendo con posturas dualistas, abriendo y permitiendo posibilidades posibles al mundo educativo, en específico la acción docente con énfasis en su relación; en otras palabras, cómo encarna o vive su experiencia el docente.

El conocimiento encarnado en este proceso se entiende como un estado de aventura incierta que comporta permanentemente el riesgo de la ilusión y del error superando las peligrosas certidumbres doctrinales, dogmáticas e intelectuales que son responsables de las mayores cegueras e ilusiones (Morín, 2001).

La relacionalidad didáctica se construye en función de cómo entendamos los roles educativos, dando énfasis al complemento, complicidad y compromiso en función de los roles, donde el contacto de piel crea un clima acogedor, la clase recibe a los estudiantes y hace que estos tengan mejor disposición a los temas que se comparten. Romper con la barrera que impone el docente sobre los estudiantes creando un clima empático y rico de aprendizaje en el aula.

La acción docente se fortalece en la medida que se encarne el contenido que se quiere compartir, es por esto que el guía (docente) de guías (estudiantes), en su acción "debe" ser él, sin caretas, proyectar desde la sinceridad su actuar, superar los roles impuestos y destacar las responsabilidades e identidades que poseen los docentes y estudiantes.

\section{Principios orientadores}

- Manejar la incertidumbre como instancia de creación, superando la confusión que retiene y desorienta.

- Velar por la intersubjetividad que enriquezca los acuerdos que la dinámica didáctica requiera.

- Inclusión didáctica que promueva la riqueza de la participación del otro, como un otro válido en la coconstrucción del proceso.

- Promover la igualdad como seres y la distinción en los énfasis que cada rol educativo genera. 


\section{Nuevas Preguntas}

¿Educo o me re-educo en la intensión de educar a otro?

¿Cómo lidiar con las costumbres del proceso formativo ya que ciegan el andar y cierran las posibilidades?

\section{Referencias}

Bertoglia R.L. (2005). La interacción profesor-alumno. Una visión desde los procesos atribucionales. Psicoperspectivas. Individuo y Sociedad, 4(1), 57-73.

Flores, R. (2009). Observando observadores. Una introducción a las técnicas cualitativas de investigación social. Chile: Ediciones Universidad Católica

Freire, P. (2005). Pedagogía del oprimido. México: siglo XXI.

Freire, P. (1997). Pedagogía de la autonomía. Brasil: Siglo XXI editores.

Mata, F., \& Medina, A. (2005). Didáctica general. España: Editorial Pearson Educación.

Maturana, H. (1991). El sentido de lo Humano. Chile: Dolmen Ediciones.

Medina, A. \& Salvador, F. (2002). Didáctica general. Madrid, España: Editorial Pearson.

Morín E. (2001). Los siete saberes necesarios para la educación del futuro. España: Paidos.

Murcia, N., \& Jaramillo, L.G. (2008). Investigación cualitativa: la complementariedad. Colombia: Editorial Kinesis.

Rodríguez, G., Gil, J., \& García, E. (1996). Metodología de la investigación cualitativa. Málaga: Aljibe.

Souto, M. (2003). Hacia una didáctica de lo grupal, Argentina: Miño y Dávila.

Sidorkin, A.M. (2007). Las relaciones educativas. España: Octaedro.

Toro, S.A. (2007). Investigaciones. Una aproximación epistemológica a la didáctica de la motricidad desde el discurso y práctica docente. Estudios Pedagógicos XXXIII (1), 29-43.

Toro, S., \& Niebles, G. (2011). Cuerpos vividos y dinámicas relacionales en el escenario escolar: una mirada desde la fenomenología. Diálogos educativos, (21), 132-156.

Trigo, E. y Equipo de investigación Kontraste. (2006). Motricidad y creatividad en la escuela. Revista Motricidad y persona, 1, 25-38.

Vayer, P., \& Roncin, Ch. (2000). Psicología das actividades corporais. Lisboa: Instituto Paiget. 


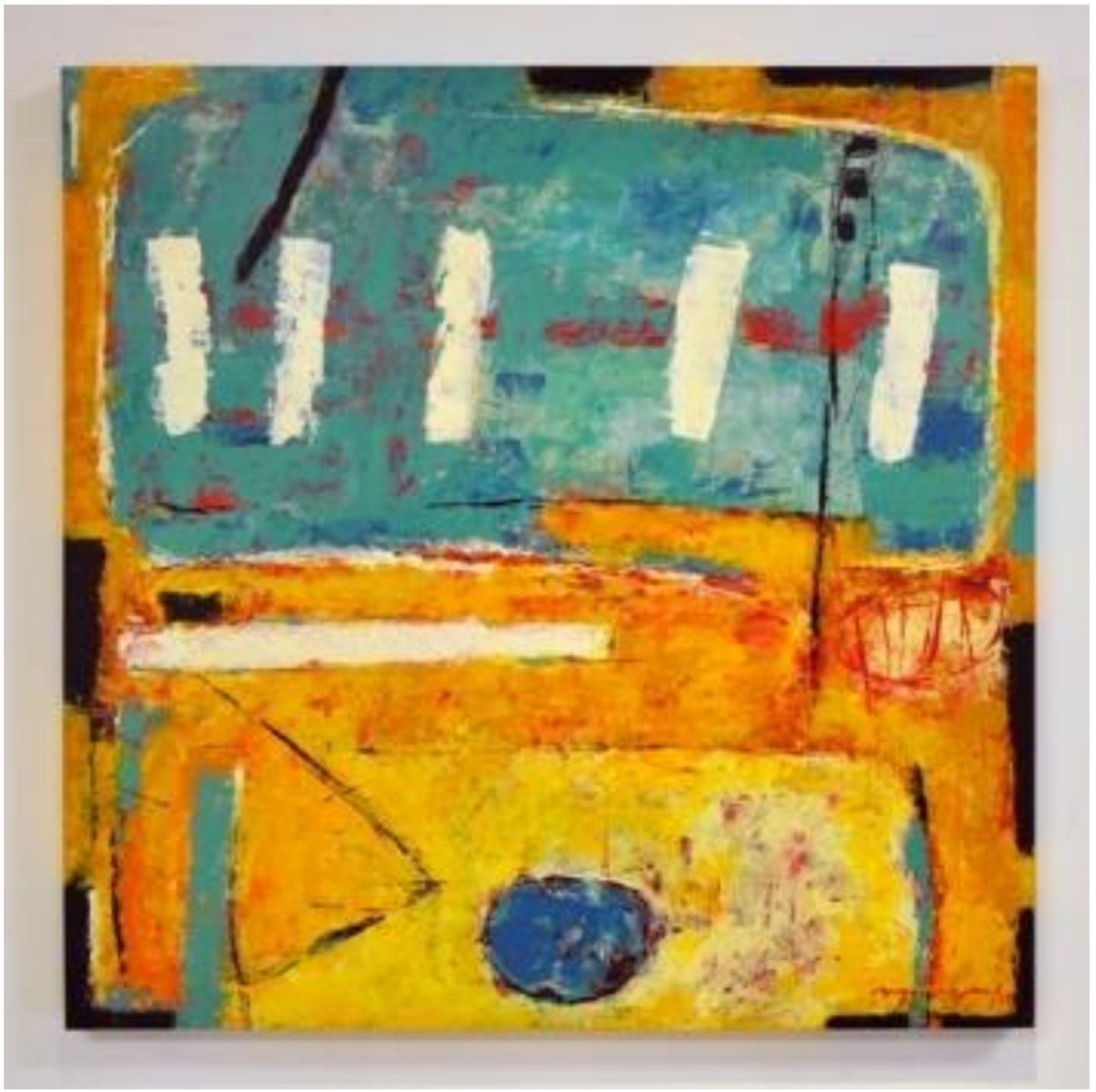

Título de la obra: Señales

Técnica: pigmentos industriales sobre polietileno

Dimensiones de la obra: $80 \mathrm{cms}$ x $80 \mathrm{cms}$

Añ $0: 2012$

Nombre de la imagen adjunta: 005 